\title{
Stimulating Learners' Motivation in Primary Education in Sri Lanka - A Literature Review
}

\author{
http://dx.doi.org/10.3991/ijet.v9i1.2964 \\ H.K.T.C Halloluwa ${ }^{1}$, Hakim Usoof $^{2}$, K.P Hewagamage ${ }^{2}$ \\ ${ }^{1}$ Sri Lanka Institute of Information Technology, Malabe, Sri Lanka \\ ${ }^{2}$ University of Colombo, Colombo, Sri Lanka
}

\begin{abstract}
Information and Communication Technology has become a vital part in the non-traditional teaching and learning environment in primary education. There is an abundance of research work that describes success stories of the practical application of information technology in primary education. Even though it is easier to motivate these young learners in the developed world to use computers, it is an arduous task in developing countries like Sri Lanka due to reasons such as the applications not being suitable for the local context. This in turn has de-motivated learning facilitators to make use of computing aids in teaching programs. This paper highlights some of the issues that the primary school learners of developing countries are facing, the current educational systems and the potential contribution of technology and game based learning in primary education. It also discusses the use of computer games in teaching and learning with an analysis of different types of games such as simulations, serious games and edutainment systems. Furthermore the paper discusses the technological aspect of learning and the opportunities that arise with the introduction of tablets in teaching. Finally the paper discusses the possibility of establishing an ICT-enabled learning environment employing a Learning Management System and tablets to use games as learning modality in primary education.
\end{abstract}

Index Terms-Technology in Learning, Primary Education in developing countries, Game based learning for children, Tablet devices in education,

\section{INTRODUCTION}

Two of the key aims of primary education in Sri Lankan are to ensure full participation of children between the ages five and ten years in primary education and one hundred percent of these children attaining the Essential Learning Competencies targeted through primary education [1]. Sri Lanka has a literacy rate of 91.2 percent with a 1:20 teacher to student ratio [2] which makes Sri Lanka a country with a high education standard for a developing country. However, these statistics hide critical problems of the education sector in rural areas. Two of these problems are the unequal distribution of teaching resources and lack of qualified teachers, which in the end decrease the quality of education [3]. Furthermore, the shortage of qualified teachers is not only observed in rural areas but also within the city areas or suburbs of Colombo [3], the teacher to learner ratio for graduate teachers in the Western province is for instance 1:53 while in the Eastern and North-central provinces the ratios are 1:79 and 1:71 respectively [2]. Table 1 gives the ratio for all nine provinces of Sri Lanka.

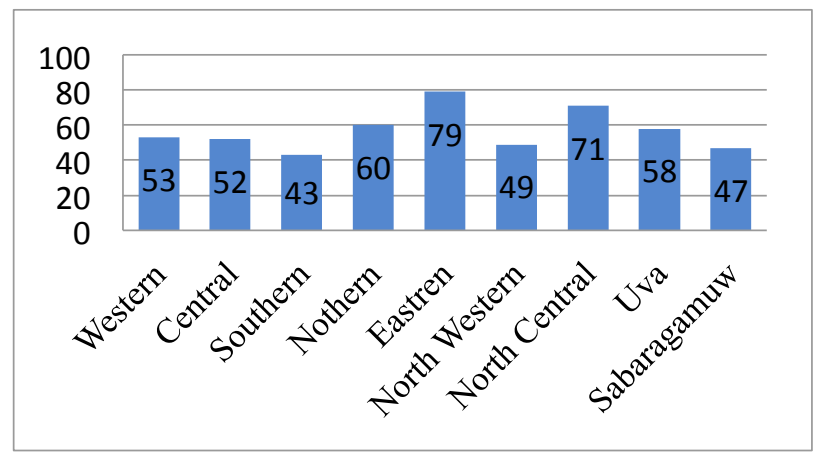

Table 1. Provincial wise Graduate teacher to Student ratio (Data Source: Department of Census and Statistics)

In 2009 the United Nations Development Programme Report concluded that 50 percent of the population within the age group of 25 years and above did not have primary education while 16 percent of the population in rural areas and 11 percent of urban population did not receive a primary education. According to school census data of 2010, most rural areas in many districts did not have primary level English language teachers. Moreover even in the junior secondary level, learners are facing challenges coping with Science \&Technology and Mathematics, the proportion of learners scoring above 50 percent in grade eight Science and Technology being only 2.8 percent during the period from 2005 to 2008 [3]. As a result there is a huge gap between the skills meant to be achieved and the actual skills achieved.

Presently the teaching and learning approach in primary education in Sri Lanka is generally teacher-centric and individualistic learning [4]. The teachers conduct classes and activities for a large number of learners and the assessment results and feedback are not provided timely. Thus the learners receive limited attention from the teacher learning is not reinforcement. Furthermore, the lessons are taught at the pace of an averagely competent student. Hence, the children who are slow learners face difficulties in keeping up with the rest of the class and rarely get a chance to reinforce their learning, while the more competent learners are left idle waiting for the rest of the class to catch up.

In addition to teaching and learning techniques and access to resources, motivation plays a key role in learning. Researchers have found that, when a child first enters a school they are very excited about learning hence motivated. But, this motivation tends to decrease over time [5]. If the child is not interested in the instruction given, it could be identified as one of the root causes that diminishes this enthusiasm and motivation of a child [6]. Motiva- 
tion can also be categorized into intrinsic and extrinsic motivation [7]. The activities that children engage in because they desire to do so are due to intrinsic motivation, while the activities that they engage in to please an external individual (e.g. teacher or parents) are due to extrinsic motivation. The high teacher-learner ratio and the lack of adequate feedback from teachers for learners to effectively continue their education can have an adverse effect on the motivation of learners.

However, solving the issues of lack of qualified teachers and other resources is a socio-political and socioeconomic concern. This paper focus on how a technologybased environment could be used to support primary education, by examining the problems cause by the lack of qualified teachers and resources. The paper also looks at game-based learning as a viable solution for the identified problems in primary education in rural areas of Sri Lanka. This paper analyses the alternative approaches that can be adapted by exploring various technological devices, environments and game-based pedagogies to improve the efficiency and effectiveness of primary education by intrinsically and extrinsically motivating a child to engage in learning.

\section{TRADITIONAL VS. NON TRADITIONAL LEARNING}

This section discusses what traditional and nontraditional learning is and the role of information technology in learning with the existing ICT enabled learning environments.

\section{A. Traditional Learning}

In the tradition leaning environment, most often the teacher is the centre of education. All power in this environment lies with the teacher and the teacher is the one who makes the decisions. For example, "What to teach?", "How to teach?", and "When to teach?" The teacher is seen as the individual with all the knowledge and the learners are at the receiving end of facts, information and skills. Some researchers even argue that, the traditional teachers think of learners as "Knowledge holes" which require filling with information [8].

Generally, primary education needs to be teachercentric environment since those learners need a close supervision. Some researches define teachers as "motivational socializers"[9].

\section{B. Non-Traditional Learning}

The introduction of information technology to education has revolutionized teaching and learning methods. The revolution has gone beyond just reading materials on the internet and nowadays people may learn by watching videos, listening to pod casts and even playing games. People can now decide what they want to learn and when they want to learn by enrolling for online courses through educational systems such as Coursera [10], Udacity [11] and Khan Academy [12] or just by visiting websites. Learners do not have to go and sit in a physical classroom to learn, they can learn at home with a computer, a tablet or a smart phone. Through the use of virtual classrooms, a learner can even attend a class with peers without being present physically. SecondLife is an example for this mode of virtual classrooms [13].

\section{ICT ENABLED LEARNING}

\section{A. The Role of computers in the traditional classroom}

The use of computers in the classrooms was started as a supplementary tool in the ICT enabled classrooms, where learners play with computers available in another room or a different section of classroom. When teaching, they were not permitted to use computers. The authoritative structure of traditional-teaching governed how computers were used in the classroom.

\section{B. T-learning/T-teaching}

T-learning refer to use of TV or radio for educational purposes. TV programs have the potential to help a child learn and are considered as a tool for distance education. An example for T-leaning programme is Sesame Street, which teaches basic knowledge and life skills required by a child. In one episode it teaches how to get things in the order one wants [14]. In addition to these type of programmes, cartoons and animations are very powerful instruments for learning but in most cases are only used for entrainment. Currently there is a trend towards prerecorded audio and video lectures are been used as a learning source for learners. The recorded set of lectures is broadcasted so that learners can view or listen to lectures from home [15]. Furthermore, there are live broadcast lectures that learners can access from home and also participate in by asking and answering questions, using Google hangouts

However because the television in itself supports only one-way communication the user interaction is very limited. Therefore, a child learner will not get any interaction experience or feedback. Researchers have found that to get an effective learning experience the child needs an aid from an adult [16]. Another disadvantage of T-learning is that the time slots are fixed for programs. Hence, if a student misses one episode, there is no way of watching it again. However, the technology is evolving and with the introduction of IP TV where it is possible to rewind and watch the missed episodes, e.g.: peoTV

\section{Web based applications}

The use of learning software and websites is another way of using technology for the purpose of learning.Even though there are several software, web applications developed to assist the learners in education, most of the applications are in English. According to UNESCO, the instructions given in local language (Mother tongue) is the key to effective learning. In fact, several case studies done in countries where English is the second language revealed that the students who followed mother-tongue based bilingual education programs [17] display superior academic achievements, superior mathematics achievements to that of students in the second-language systems. Furthermore, their achievement in second language is as high as the second language system children and they acquire additional expertise in the first language while participating more actively in the learning activities and feel more confidence about learning. [17]

The affordances of the web as a potential learning tool has also been identified by the Ministry of Education, which had has led to the "E-Thaksalawa" (e-School) initiative [18]. This allows Sri Lankan children to participate in educational activities related to their school curriculum. However, the effective use of these applications depends 
on the learning support that the application is providing and also the bandwidth of Internet. Some of the activities on this initiative require a considerable amount of adult assistance not on subject matter but on how to handle the functionalities of the application.

This section identifies the importance of ICT enabled learning/teaching environment. In the context of child learning, the role of a teacher is important irrespective of environment. However, an ICT enabled environment could bring additional benefits to aid children in learning [9, 19]. It has also been found that assessment results of learning achieved through the use of ICT enabled learning are higher than the assessment results of learning achieved through traditional learning methods [20].

\section{GAMES AND LEARNING}

Computer games have become one of the most preferred activities among the younger generation. The younger generation spend ten thousand hours playing games and twenty thousand hours watching TV before graduating, but they only spend five thousand hours reading [21]. Therefore, there is a necessity to change the modes of learning by attempting to link learning with the preferred activities of the younger generation. Ellen Langer in the book titled "The power of mindful learning" suggests that "Play holds our attention because the stimulus is constantly changing" [22]. According to the author even when reading a book if the readers engage with it and imagine themselves as the characters, the reader will get a better learning experience. Some researchers point out that there is a gap between the things that the children are doing for fun and the things required by schools [23]. However, games have been found to be highly engaging and motivating [23].Thus if games can be used to develop the knowledge and skills required, it could get the full attention of the users which leads to a better learning experience

\section{A. Digital games}

Games can be used to help children achieve higher targets in education and it can be a powerful teaching tool [24]. Recent researches strengthen this idea and have found that computer games which consist of both fun and motivational features can be used as a mean to improve and strengthen the quality of education [25]. Games also provides an environment where you can learn by making mistakes without any adverse consequences. Video games such as Tetris can enhance the spatial cognition abilities of players while some games can be used to improve prosocial behavior [26]. It can also be used as a tool for pain management for kids [26]. Several research studies has proved that playing computer games is an effective way of learning difficult subjects such as mathematics. A further study has also been carried out to determine the importance of 3D characters and environments in video games. This study found that when the children were exposed to classic video games which were popular in $90 \mathrm{~s}$ they got frustrated and de-motivated [27].

\section{B. Serious Games, Edutainment systems and Simulations}

Serious games, Edutainment systems, Simulations are terms that are closely related when games for education is concerned.

Games and Simulations are seemingly similar things but with a major difference, which is "fantasy" [28]. Most modern games based on fantasy whereas simulations are based on real life scenarios. There are some simulations turned into games such as Flight Simulator. They were originally introduced to train pilots, but now Microsoft Flight Simulator [29] has become a popular game.

The term "Edutainment" refers to educational entertainment. Here an edutainment system can be defined as anything that provides education along with entertainment. Thus, an edutainment system is not exclusive for games but may also be movies, documentaries, radio programs and educational toys such as Lego Bricks, Leap pads [30].

Serious games have been defined in many ways. "A serious game is a game in which education (in its various forms) is the primary goal, rather than entertainment" [31]. A few examples are the "Global Conflict Series", " 3 rd world farmer" and "Budget Hero". Thus a serious game can be defined as a computer or a video game that has a "serious" purpose other than pure entertainment. Another definition for serious games is "A mental contest, played with a computer in accordance with specific rules that uses entertainment to further government or corporate training, education, health, public policy, and strategic communication objectives"[32].This definition manages to bridge the gap between simulations and serious games. Figure 1 emphasizes the difference between a game and a serious game.

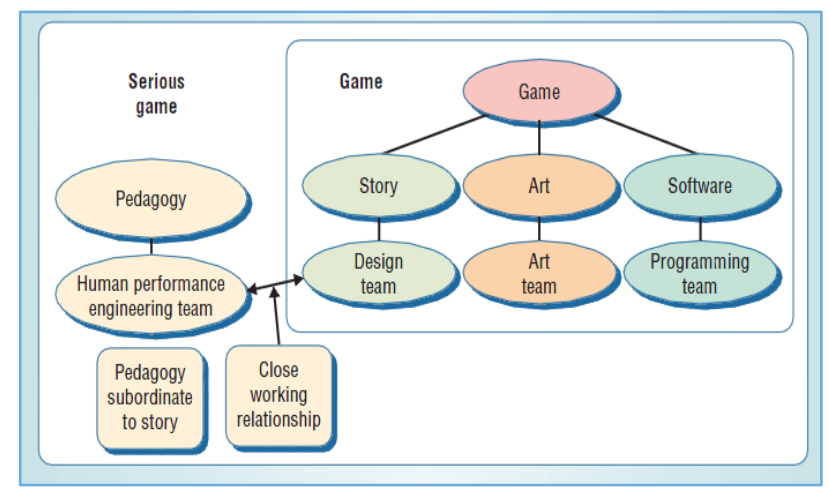

Figure 1. The difference between serious games vs. normal games [32]

Unlike the video games, which are purely based on entertainment, serious games use pedagogy to incorporate learning experience while keeping the entertainment intact. Serious games employ the use of a human performance engineering team which maintains a close relationship with the game design team as well. Several serious games have been implemented for the use of children. LudoMedic formally known as MediKids is an example, which focuses on kid's hospitalization [33]. "Escape from Diab" [34] teaches about dietary habits and nutrition. "ReMission" [35] is another game that specifically focus on children.

Children love to play. Then they like to play digital games too. Five factors of learning are achieved when a child plays a game. That is learning why, what, when, where and how. Through these factors they learn about real life and about strategy [36]. Education Scotland identifies several game based learning for children, among them are [37];

- Motivates learners to improve continuously

- Improves self-esteem, self-determination and selfimage 
- Facilitates collaborative learning

- Develops ability to observe, question and test

- Develops complex problem-solving skills

According to United states department of education "assessment technologies, such as simulations, collaborative environments, virtual worlds, games, and cognitive tutors, can be used to engage and motivate learners while assessing complex skills" [38] and researchers identify that while in general digital games can be used to facilitate learning, more research is needed on the matter of "how games can best be used in learning" [39]

\section{USE OF TABLET DEVICES IN EDUCATION}

With the advancement of technology a collection of new devices such as smart phones and tablet devices are being used in the field of education. According to researchers [40] there is a great potential for tablet devices to be used for educational purposes as opposed to traditional desktop computers. John Traxler argues that "Interacting with a desktop computer takes place in a bubble, and in dedicated times and places where the user has his or her back to the rest of the world for a substantial and probably premeditated episode. Interacting with mobile technologies is different and is woven into all the times and places of students' lives..." Furthermore, Traxlor argues that desktop technologies can be ignored but not mobile technologies because desktop technologies operate in their own confined world while mobile technologies operate in the world [40].

In the discussion on using tablet devices to teach children in rural areas, one challenging point is the cost of such devices. The "One Laptop per Child" (OLPC) [41] is an initiative based on the hypothesis that a computer can make a drastic change to the way children are learning and this project has been successfully carried out in various developing countries including Sri Lanka [42]. One success factor behind this project was the fact that the total cost of the device is of one hundred US dollars [42]. Today, there are tablet devices available in the market that cost less. An example for this is the Indian Pad which only costs thirty-five US dollars. Still the usage of tablet devices for child education is at a minimum level in most developing countries, but several case studies have provided evidence that the use of tablet devices improves the effectiveness of child education [43].

In ICT enabled learning environments computers, mobile phones and tablet devices are becoming a medium for users to connect with the learning environments [43].Tablet devices definitely will play more prominent role according to recent studies [40 ],[48].

\section{LEARNING MANAGEMENT SYSTEMS AND PRIMARY EDUCATION}

A learning management system (LMS) is a great environment for learning, evaluating, and tracking progress. It allows the learners access to learning materials from anywhere in the world and it also provides means to track and evaluate the learners' performance through a single unit. Researchers has defines LMS as "An infrastructure that delivers and manages instructional content, identifies and assesses individual and organizational learning or training goals, tracks the progress towards meeting those goals, and collects and presents data for supervising the learning process of an organization as a whole An LMS delivers content but also handles course registration and administration, skills gap analysis, tracking and reporting" [46]. Even though this is a widely used tool for higher education, the use of this tool for primary education is limited. Some of functionalities may not be good and will create unnecessary complication for learners. For example the login, selecting courses, modules and attempting quizzes.

\section{DisCUSSION}

The statistics prove that ninety-four percent of Sri Lankan children of the age group 5-14 learn at school and one percent from other educational institutes and five percent do not receive primary education [3]. Thus we could conclude that a large proportion of children spend between 25-30 hours at school. However due to lack of resources, high teacher to student ratios and various other issues mentioned in this paper, the children in the rural areas do not receive a quality primary education.

It has also been identified that there are various types of computer and video games that can be used in a classroom environment for learning purposes. In addition a variety affordance of games such as motivating children to continuously improve, developing complex problem solving skills and facilitate collaborative learning have been identified to support the use of games for the purpose of learning. It also makes the class room a fun place to be [37]. Nonetheless to provide a successful learning experience for children a good pedagogy is required by the teachers.

The use of tablet devices for learning promotes the concept of Mobile Learning [44] where the learner learns on the move. Combining this with the fact that computer games can be used as a media to teach children, it is reasonable to conclude that games, which are running on tablet devices, have a high likelihood of being the future medium of child education since play is a highly engaging and motivating activity [45].The size and the weight of a Tablet device make it an ideal portable learning device [47]. They are highly intuitive since most of the interaction is done through gestures, movements and touch instead of a traditional keyboard and mouse [47]. Additionally, it's affordable and cheaper than a laptop or a desktop computer. Since the Sri Lankan government identifies ICT is the key to reform Sri Lanka through its "eSri Lanka" initiative [48], it might be used to distribute cheap but effective tablet computers among students in rural areas. Since most of Sri Lanka's mobile internet providers and broadband internet providers provides internet coverage to most provinces of the country [49] [50], having internet connectivity will not be a huge issue.

The work being done, the games being played need to be tracked to identify the areas of difficulties for a child. It's also important to know the progress being made. The learning management systems are being used for this purpose in Sri Lankan higher education but the use of this software is not in use for primary education. In the context of children, a learning management system could provide unnecessary complications due to various functionalities. A child will need a device which they could use to play. And the game could guide them through an educational journey. The performance could automatically be recorded in the learning environment so that an adult could track the progress. 
Hence if a learning management system can be introduced specifically for children, which allows them to play educational games related to what they are learning in the school using a tablet device, it could provide a solution for the issues identified in the primary education of developing countries.

\section{REFERENCES}

[1] Primary Education Branch, Ministry of Education Sri Lanka, "Specific Objectives". Internet: http://www.moe.gov.lk/web/ index.php?option $=$ com content\&view $=$ article \&id $=121 \% 3 \mathrm{~A} 2011$ 01-11-08-57-00\&catid=104\%3A2011-01-16-17-07-04\&Itemid= 78\&lang $=$ en [Accessed May 10, 2013]

[2] Department of Census \& Statistics Ministry of Finance \& Planning, "Annual Bulletin of Education Statistics, Annual School Census", 2010 [Accessed_May 10, 2013]

[3] United Nations Development Program Sri Lanka, Sri Lanka Human Development Report 2012, Bridging Regional Disparities for Human Development, Internet: http://hdr.undp.org/en/reports/ national/asiathepacific/srilanka/Sri\%20Lanka\%20Human\%20De velopment\%20Report\%202012.pdf [Accessed May 10, 2013]

[4] Ananda Mahto, Internet: http://ananda.mahto.info/an-individua listic-approach-to-education/ [Accessed Sep 13, 2013]

[5] Kathryn M Edmunds, Kathryn L Bauserman "What teachers can learn about reading motivation through conversations with children", The Reading Teacher, (International Reading Association (pp. 414-424), Vol. 59, No. 5 February 2006)

[6] Allan Wigfield and John T. Guthrie, "Engagement and motivation reading". (Handbook of reading research Vol. 3; pp. 403-422, 2000) available: http://www.readingonline.org/articles/handbook/ guthrie/

[7] Allan Wigfield and John T. Guthrie, "Relations of Children's Motivation for Reading to the Amount and Breadth of Their Reading", Journal of Educational Psychology, Vol. 89, No. 3,pp: 420432, 1997 http://dx.doi.org/10.1037/0022-0663.89.3.420

[8] Tonia T. Lennox, "Education towards Integration: an alternative prgramme". M.E. thesis, University of South Africa, South Africa, 2009

[9] Kristina Mullamaa , "ICT in Language Learning - Benefits and Methodological Implications", International education studies, (Vol 3 No 1,February 2010)

[10] Cousera. Internet: https://www.coursera.org/ [Accessed December 13, 2012]

[11] Udacity. Internet: https://www.udacity.com/courses [Accessed December 13, 2012]

[12] Khan Academy. Internet: https://www.khanacademy.org/ [Accessed December 13, 2012]

[13] Second Life. Internet: http://secondlife.com/ [Accessed January $15,2013]$

[14] Gerald S. Lesser, "Learning, Teaching, and Television Production for Children: The Experience of Sesame Street", Harvard Educational Review (Journal) pp: 232-272, January 03, 2012

[15] Education Department of the Corporation for Public Broadcasting, Center for Children and Technology, "TELEVISION goes to SCHOOL: The Impact of Video on Student Learning in Formal Education", 2004, Available: http://www.dcmp.org/caai/nadh 173.pdf

[16] Bryce, J. W. \&Leichter, H. J. (1983). "The family and television: forms of mediation". Journal of Family Issues, Vol. 4, No. 2 pp. 309-328, June 1983 http://dx.doi.org/10.1177/019251383004 $\underline{002004}$

[17] D Bühmann and B Trudell, "Mother tongue matters: local language as a key to effective learning", 2007, Internet http://unesdoc.unesco.org/images/0016/001611/161121e.pdf [Accessed September , 2013]

[18] E-thaksalawa. Internet: http://www.e-thaksalawa.moe.gov.lk/web/ [Accessed May 30, 2013]

[19] Yves Punie, "Learning Spaces: an ICT-enabled model of future, learning in the Knowledge-based Society", European Journal of Education,(Vol. 42, No. 2, 2007) http://dx.doi.org/10.1111/j.14653435.2007.00302.x
[20] B. Means, Y.Toyama ,R.Murphy,M. Bakia,K. Jones "Evaluation of Evidence-Based Practices in Online Learning a Meta-Analysis and Review of Online Learning Studies" Internet: http://www.ed.gov/rschstat/eval/tech/evidence-based-practices/fin alreport.pdf, 2010

[21] Marc Prensky,'Digital Natives, Digital Immigrants", On the Horizon (MCB University Press, Vol. 9 No. 5, October 2001)

[22] Ellen Langner. "The power of mindful learning", Harvard University, Department of Psychology, 33 Kirkland Street Cambridge, 1998

[23] J. Shute, Lloyd Rieber, and Richard Van Eck "Games ... and ... Learning" Internet: http://myweb.fsu.edu/vshute/pdf/shute \%20pres_i.pdf [Accessed: May 13, 2013]

[24] Barlett CP, Anderson CA, and Swing EL, "Video game effects confirmed, suspected and speculative: A review of the evidence." Simulation and Gaming, pp: 377-403. (2009). http://dx.doi.org/ 10.1177/1046878108327539

[25] Yuh-Ming Cheng, Shi-Jer Lou, Sheng-Huang Kuo and Ru-Chu Shih "Investigating Elementary School Learners Technology Acceptance by Applying Digital Game Based Learning to Environmental Education", Australasian Journal of Education Technology, Vol 29, No 1 (2013)

[26] Craig A Anderson and Wayne A Warburton, "The impact of violent video games: An overview" in Growing Up Fast and Furious: Reviewing the Impacts of Violent and Sexualized Media on Children, Annandale, NSW, Australia: The Federation Press. Chapter 3 (pp. 56-84).

[27] HakanTüzüna, MeryemYılmaz-Soylua, TürkanKarakuşb, Yavuzİnalb and GoncaKızılkayaa . "The effects of computer games on primary school learners' achievement and motivation in geography learning" Computers \& Education Volume 52, Issue 1, January 2009, Pages 68-77

[28] Dennis Charsky,"From Edutainment to Serious Games: A Change in the Use of Game Characteristics", SAGE Journals, games and culture, April 2010 vol. 5 no. 2 pp177-198

[29] Microsoft Flight Simulator, Internet: http://www.microsoft.com/ games/flightsimulatorx/ [Accessed May 5, 2013]

[30] Leap pads, Internet: http://www.leapfrog.com/en/landingpages/ leappadultra.html/ [Accessed_May 5, 2013]

[31] Johannes Breuer, Gary Bente, "Why so serious? On the Relation of Serious Games and Learning" Journal for Computer Game Culture. 2010; Vol4, pages. 7-24

[32] Michael Zyda, "From Visual Simulation to Virtual Reality to Games ". IEEE Explore, Vol: 38, Issue: 9, 2005, Pages 25 - 32

[33] LudoMedic, Internet: http://www.ludomedic.com/ [Accessed_May $5,2013]$

[34] Escape from Diab, Internet: http://www.escapefromdiab.com/ [Accessed_May 5, 2013]

[35] Re-Mission, Internet: http://www.re-mission.net/ [Accessed_May $5,2013]$

[36] Marc Prensky,"What Kids Learn That's POSITIVE From Playing Video Games" ,2002

[37] Education Scotland, "About game based learning", Transforming lives through learning. Internet: http://www.educationscotland. gov.uk/usingglowandict/gamesbasedlearning/about/understanding. asp [Accessed: June 20, 2103]

[38] U.S. Department of Education. "'Transforming American education: Learning powered by technology". 2010, page 15 Internet: http://www.ed.gov/sites/default/files/netp2010-execsumm.pdf [Accessed Sep 19,2013]

[39] K L. McClarty,A. Orr,P M. Frey,R P. Dolan,V. Vassileva,A. McVay , "A Literature Review of Gaming in Education", 2012, Internet: http://www.pearsonassessments.com/hai/Images/tmrs/ Lit_Review_of_Gaming_in_Education.pdf [Accessed Sep 19, 2013]

[40] John Traxler, "Will Student Devices Deliver Innovation, Inclusion, and Transformation", Journal of the Research center for Eductaion technology, Vol 6, 2010, pages 3-15

[41] OLPC, One laptop per child ,Internet : http://one.laptop.org/ [Accessed January , 2013]

[42] K. P. Hewagamage1, H.M.S.J.Meewellewa, G.K.Munasinghe,H.A.Wickramarachi, "Role of OLPC to Em- 
PAPER

Stimulating Learners’ Motivation In Primary EdUCATIOn In SRi LANKA - A Literature ReVieW

power ICT Adaptation in the Primary Education", Education in a technological world: communicating current and emerging research and technological efforts. 2011. Pages 391-398

[43] Victoria Australia, Department of educationadn early childhood development, "I-Pads for Learning", Internet: http://www.ipadsforeducation.vic.edu.au/ipad-education-casestudies/3-manor-lakes-p12-specialist-college [Accessed April 1, 2013]

[44] Mobile Learning, UNESCO, "ICT in Education", Internet: http://www.unesco.org/new/en/unesco/themes/icts/m4ed/

[45] M Hyson, "The role of play in promoting children's positive approaches to learning", Internet: http://www.researchconnec tions.org/files/childcare/pdf/PlayandApproachestoLearningMarilouHyson-1.pdf

[46] William R. Watson and Sunnie Lee Watson, "An Argument for Clarity: What are Learning Management Systems, What are They Not, and What Should They Become?", TechTrends ,2007 vol:51 No :2

[47] Melhuish, K. \&Falloon, G,“ Looking to the future: M-learning with the iPad". Computers in New Zealand Schools: Learning, Leading, Technology, Vol 22 (2010)
[48] eSri Lanka Internet : http://www.icta.lk/en/e-sri-lanka.html [Accessed : Sep 19, 2103]

[49] Mobitel Coverage Internet: http://www.mobitel.lk/coverage [Accessed: Sep 19, 2103]

[50] Dialog Coverage: Internet: http://www.dialog.lk/support/mobile/ coverage-service-points/3g-coverage-map/ [Accessed : Sep 19, 2103]

\section{AUTHORS}

H.K.T.C Halloluwa is with the Sri Lanka Institute of Information Technology, New Kandy Rd, Malabe , Sri Lanka (thilina.h@sliit.lk).

Hakim Usoofis with the University of Colombo School of Computing, UCSC Building Complex,35 ,Reid Avenue, Colombo 7, Sri Lanka (hau@ucsc.cmb.ac.lk).

K.P Hewagamage is with the University of Colombo School of Computing, UCSC Building Complex,35 ,Reid Avenue, Colombo 7, Sri Lanka (kph@ucsc.cmb.ac.lk).

Submitted 29 June 2013. Published as re-submitted by the authors 23 January 2014 